\title{
Ética, política e religião nas conversações on-line sobre laicidade e diversidade em demandas morais por justiça'
}

Ethics, politics and religion in online conversations on laity and diversity in moral demands for justice

Ética, política y religión en las conversaciones online sobre laicidad y diversidad en demandas morales por justicia

Bruno Menezes Andrade Guimarães

- Doutorando em Comunicação Social pelo PPGCOM da Universidade Federal de Minas Gerais (UFMG)

- Mestre em Comunicação Social pela UFMG

- Bacharel em Comunicação Social com habilitação em Jornalismo pela Universidade Federal de Viçosa (UFV)

- Membro do Grupo de Pesquisa em Democracia e Justiça (Margem) e identifica-se com pesquisas relacionadas à política e sua interface com a religião e as mídias digitais.

- Bolsista da Fundação de Amparo à Pesquisa de Minas Gerais (Fapemig)

- E-mail: brunomenezesag@gmail.com

Angela Cristina Salgueiro Marques

- Doutora em Comunicação Social pela Universidade Federal de Minas Gerais (UFMG)

- Fez estágio pós-doutoral na Université Stendhal, Grenoble III

- Professora do Programa de Pós-Graduação em Comunicação Social da UFMG

- Pesquisadora associada ao Grupo de Pesquisa em Democracia e Justiça (Margem) - DCP-FAFICH

- Autora, junto com o professor Luis Mauro Sá Martino, da obra Mídia, ética e esfera Pública

- E-mail: angelasalgueiro@gmail.com 


\section{Resumo}

0 artigo se propõe a analisar as interações de pessoas comuns no Facebook a partir de uma notícia acerca de reivindicações de pessoas LGBTQ por respeito à diversidade e à laicidade do Estado, isto é, contra os projetos de lei e as imposições de alguns parlamentares religiosos. A questão que se coloca, muito ligada ao campo da comunicação, é entender em que medida a relação entre religião e política se constitui nas trocas conversacionais, ou seja, observar como os modos de operação da política são postos em disputa e são midiática e discursivamente tensionados. Nosso objetivo é, portanto, captar os sentidos evocados pelo tema da laicidade e compreender quais são as concepções (argumentos, perspectivas) trazidas à tona por esses públicos que oferecem contornos éticos aos embates na internet ao se engajarem em disputas de sentido em torno da relação entre religião e política nos meandros da sociedade brasileira.

PALAVRAS-CHAVE: CONVERSAÇÃO POLÍTICA • FACEBOOK •ÉTICA • LAICIDADE • GÊNERO.

\section{Abstract}

The objective of this article is to analyze the interactions of common people on Facebook to news articles on LGBTQ+ claims for respect to diversity and the laity of the State, i.e., against some law projects and impositions of some religious parliamentarians. The question, related to the Communication field, consists of understanding the relation between religion and politics in conversational exchanges, i.e., to observe how politics modes of operation are disputed and pressured in mediatic and discursive ways. Therefore, our main objective is to understand the senses evoked by the laity subject and to understand which are the conceptions (arguments, perspectives) brought up by these groups of people that present ethical outlines to online discussions when they engage on meaning disputes on the relation between religion and politics in the context of the Brazilian society.

KEYWORDS: POLITICAL CONVERSATION • FACEBOOK • ETHICS • LAITY • GENDER.

\section{Resumen}

El artículo se propone a analizar las interacciones de personas comunes en Facebook a partir de una noticia acerca de reivindicaciones de personas LGBTQ por respeto a la diversidad y a la laicidad del Estado, es decir, contra los proyectos de ley y las imposiciones de algunos parlamentarios religiosos. La cuestión que se plantea, muy ligada al campo de la comunicación, es entender en qué medida la relación entre religión y política se constituye en los intercambios conversacionales, es decir, observar cómo los modos de operación de la política se ponen en disputa y son mediática y discursivamente tensados. Nuestro objetivo es, por lo tanto, captar los sentidos evocados por el tema de la laicidad y comprender cuáles son las concepciones (argumentos y perspectivas) traídas a la superficie por esos públicos que ofrecen contornos éticos a los embates en Internet al involucrarse en disputas de sentido en torno a la relación entre religión y política en los meandros de la sociedad brasileña. 
0 Brasil é um país laico. A laicidade, em tese, deve assegurar o respeito à diversidade religiosa, sexual e cultural, além de garantir o direito de que cada pessoa viva de modo a confessar (ou não) quaisquer tipos de credos. Mariano e Oro (2013) dão uma definição, grosso modo, de laicidade. De acordo com os autores, trata-se de uma "regulação política, jurídica e institucional das relações entre igreja e Estado, religião e política, ou a regulação das fronteiras, do lugar e do papel do religioso e do secular nas sociedades modernas (Mariano; Oro, 2013). Todavia, ao falarmos sobre a laicidade do Estado brasileiro não nos referimos a uma definição estanque e consensual. Ao contrário, a laicidade no Brasil é um tema em disputa, constituído ao longo de um percurso repleto de peculiaridades (Giumbelli, 2008; Montero, 2012, 2013).

Waizbort (2001, p. 92), em uma leitura das obras de Simmel e Elias, e com vistas no todo relacional que constitui as sociedades, afirma que "uma teoria das relações entre as pessoas não pode prescindir justamente daquilo que faz a sociedade, sociedade, e dos homens, homens: do jogo de força que constitui as relações humanas". Quando a discussão gira em torno da laicidade no Brasil e da inserção da religião nos modos de se fazer política em nosso país, esse jogo de forças, se não mais forte, é, sem dúvida, mais explícito.

Para Taylor (2012), dizer que uma nação é laica não é o mesmo que dizer que ela é neutra com relação a valores, tampouco que essa neutralidade é possível, isso porque a sociedade é feita de seres humanos plurais. Waizbort (2001) diz que o que constitui as sociedades são (justamente) as relações entre esses seres humanos plurais, e que o conceito de interação fornece lastro para a concepção do todo relacional. Ora, se nos referimos a interações entre pessoas portadoras de diferentes visões de mundo, é de se esperar que haja conflito nas interações estabelecidas entre elas. De certo, de acordo com a sociologia simmeliana, o "conflito" é a própria natureza das relações sociais (Waizbort, 2001).

Em outras palavras, há um jogo de forças em torno da definição da laicidade do Estado brasileiro e sobre a questão da diversidade e o respeito a minorias de pessoas lésbicas, gays, bissexuais, transexuais, travestis, transgêneros, queers, intersexuais e simpatizantes, englobadas, sempre no plural, pela sigla LGBTQ. Nossos olhares estão atentos para captar parte desse jogo. É preciso suplantar a ideia de que há uma concepção irrestrita de laicidade em nosso país e olhar para os conflitos instaurados frutos da relação entre religião e política brasileira, relação que possui um histórico e que se faz presente de modo ainda mais forte nos dias de hoje. Reiteramos a frase de Taylor (2012, p. 169) que diz "pensamos que a laicidade tem a ver com a relação o Estado e a religião, quando na realidade tem a ver com a resposta correta do Estado democrático à diversidade". Apreender essas respostas é olhar para as interações, as tensões e os conflitos.

0 artigo se propõe a analisar as interações de pessoas comuns em plataformas midiáticas on-line a partir de uma notícia acerca de reivindicações do grupo LGBTQ por respeito à diversidade e à laicidade do Estado. A questão colocada, muito ligada ao campo da comunicação, é entender em que medida a relação entre religião e política é aceita ou preterida por diferentes pessoas. Nosso objetivo é, portanto, captar os sentidos evocados pelo tema da laicidade e compreender quais são as concepções trazidas à tona por elas. Estamos de acordo com um grupo de autores e autoras (Duarte, 2012; Giumbelli, 2008; Martino, 2016; Montero, 2012, 2013; Taylor, 2010, 2012; Willaime, 2012) que nos convida a refletir sobre o conceito de laicidade e as disputas de sentido em torno da relação entre religião e política nos meandros da sociedade brasileira.

Para que isso seja possível, e para fins de contextualização, em um primeiro momento partimos de uma breve reflexão acerca dos elementos éticos e morais que influenciam no processo de constituição jurídica da laicidade no Brasil. Cremos, assim como Mariano (2011), que o Brasil sofreu um processo de "laicidade à brasileira", isto é, ao seu próprio modo². A força moral que a Igreja Católica sempre exerceu, aliada a incertezas relacionadas ao sentido e ao valor da modernidade (CANCLINI, 2015),

2 Há trabalhos específicos acerca da (peculiar) constituição da laicidade nos demais países latino-americanos. Destacamos o livro organizado por Nicolás Panotto (2017) intitulado "Religiones, política y Estado laico: nuevosacercamientos para el contexto latino-americano", Redlad, 2017. 
que supostamente traria consigo um espírito laico e secularizador (TAYLOR, 2010, 2012), fez da constituição da laicidade no Brasil um processo difuso, permeado por trocas, barganhas e conflitos. Já nos dias de hoje, a atuação de certos grupos políticos pautados em preceitos religiosos é responsável por tensionar ainda mais os limites da laicidade em nosso país.

Em um segundo momento do texto, apresentamos um evento importante para as nossas análises, a Parada do Orgulho LGBT de São Paulo-SP. Destacamos a intrínseca ligação entre as reivindicações por integridade e justiça presentes na 21ā edição da Parada, a mais recente, e as lutas em prol de um Estado laico sem a mediação de preceitos religiosos nos trâmites do legislativo. Por fim, procedemos com as análises das interações entre sujeitos comuns, usuários da maior plataforma midiática do Brasil e do mundo, o Facebook. As análises são feitas por meio da leitura e das dinâmicas estabelecidas em comentários escritos acerca de uma notícia da página do jornal Folha de S.Paulo, cujo tema é a 21a edição da Parada do orgulho LGBT. Categorizamos os comentários para entender e captar os conflitos éticos e os modos como os sentidos de laicidade e diversidade são reivindicados on-line por diferentes grupos.

\section{"LAICIDADE À BRASILEIRA": CONFLITOS ANTIGOS, INTERESSES ATUAIS}

Como entender as mediações e a presença legitimada da religião no espaço público brasileiro? Para responder a essa questão é necessário ter em mente que o processo de laicidade em nosso país foi (e é) construído de uma maneira peculiar, bem como no contexto latino-americano como um todo, fruto de uma modernização tardia e de um jogo de interesses políticos entre Estado e Igreja(s). Giumbelli (2008) afirma que tanto no Brasil quanto nos demais países da América Latina a presença da religião na esfera pública não se deu em oposição ao processo de secularização ${ }^{3}$ tal como nos padrões dos países europeus, ao contrário, em países latinos, sobretudo no Brasil, "foi no interior da ordem jurídica encimada por um Estado comprometido com os princípios da laicidade que certas formas de presença da religião ocorreram" (Giumbelli, 2008, p. 81).

O marco inicial do processo de constituição da laicidade no Brasil data de 1889, ano em que a proclamação do regime republicano suscitou um amplo debate com a intenção de delimitar os direitos políticos e econômicos da Igreja Católica. Diante dos auspícios republicanos, o ensino público é declarado leigo, os cemitérios públicos são secularizados ao passo que são proclamados os princípios de liberdade e igualdade religiosa para diferentes credos, tudo inspirado em modelos de laicidade instituídos em países de primeiro mundo. Um ano depois, em 1890, Ruy Barbosa assinou o decreto 119-A e oficializou a laicidade do Brasil, feito que destituiu os efeitos civis de sacramentos da religião católica, como o batismo, o matrimônio e a extrema-unção. 0 Brasil, então, deixou de confessar uma religião oficial. Porém, a fronteira que objetivava separar religião e política era, desde já, híbrida. Segundo Montero (2013, p. 22), "a construção da laicidade brasileira se deu no contexto de um violento e permanente confronto entre os dois aparatos [Igreja e Estado] para delimitar as competências e áreas de influências".

A liderança da Igreja Católica, contrária à separação com o Estado, deu início a uma série de pressões a fim de que fosse reconhecida a preeminência do catolicismo na construção da nacionalidade brasileira, além da importância e da presença de valores éticos e morais do cristianismo na constituição da sociedade (Giumbelli, 2008; Karnal, 2017). 0 empenho da liderança católica foi, em partes, recompensado no texto da Constituição de 1934, o qual dizia, entre outros, que o ensino religioso seria permitido nas escolas e o casamento religioso recuperaria a sua validade civil. Além disso, o texto de 1934 previa um reforço à colaboração entre Estado e religiões, isto é, conferia liberdade e autonomia jurídica aos diferentes credos religiosos no Brasil4.

30 conceito de secularização está alicerçado em princípios iluministas e consiste na "racionalização das organizações modernas e na autonomização crescente das instituições e das práticas sociais com relação à religião" (Willaime, 2012, p. 157). Montero (2013, p. 14) entende que a história do secular tem relação com "o modo como o Ocidente definiu sua modernidade e a religião, em oposição ao mundo medieval".

40 texto da Constituição de 1934 é resultado de outros textos, como a Constituição de 1891, leis de 1893 e o Código Civil de 1917. 
Giumbelli (2008) aponta que a noção de "colaboração" entre o Estado brasileiro e as religiões, sobretudo a católica, foi um aporte constitucional forte para traduzir que, em meio a um país que acabara de se tornar laico, a lgreja celebrava acordos oficiais para benefícios próprios. Em outras palavras, desde o começo o processo de constituição da laicidade de uma nação subdesenvolvida e modernizada de forma tardia foi marcado pela mediação de atores religiosos em disputa com o próprio Estado por concessões e benefícios a favor da religião na esfera pública. Ainda de acordo com Giumbelli (2008), o mais interessante nesse processo é a luta da Igreja Católica pelo princípio da "liberdade religiosa" (para quaisquer religiões), pois, ao traduzir esse princípio, estava em jogo discussões sobre a autonomia jurídica das associações religiosas.

A fim de estipular a relação entre dimensões econômicas e os modos de ser de associações religiosas, o Código Civil de 1917 trouxe pontos importantes para conferir autonomia para as ações das igrejas no Brasil e reafirmar conquistas outrora celebradas por líderes católicos. Entre esses pontos, destacamos a asserção de não pesar sobre as igrejas nenhuma restrição sobre os modos de gerir dinheiro e de se relacionar com os membros (fiéis); o fato de o registro civil do estatuto de uma determinada igreja conferir autoridade jurídica, independente de autorização prévia, a essa igreja; e a afirmação de que as igrejas estão sujeitas ao mesmo regime civil de demais sociedades sem fins lucrativos. Giumbelli (2008, p. 83) diz que, de fato, "constituiu-se um fundamento jurídico para conferir personalidade aos coletivos religiosos, o que significava reconhecer a sua existência e ações legais em várias esferas"5.

Montero (2012, p. 172) entende que a religião cristã possui, desde sempre, uma primazia simbólica e política na mediação de valores para as normas, ou seja, para as leis: "Suas formas discursivas e o modo como suas categorias teológicas circulam no imaginário político, sua íntima colaboração com o Estado nas áreas sociais [...] são elementos importantes que garantem legitimidade".

Se no Brasil há consenso em torno da laicidade nos termos da lei, também há consenso que a laicidade, na prática, está em construção e em constante disputa, ou seja, entende-se que perdura um profundo dissenso em torno dos modos como a religião esteve (e está) apartada de esferas públicas, isto é, como a religião medeia a política e demais aspectos da vida (Cunha, 2017; Giumbelli, 2008; Mariano; Oro, 2013; Martin-Barbero, 2009; Montero, 2012, 2013). Uma citação emblemática de Montero (2013, p. 24), hipótese em diversas pesquisas sobre o tema, diz: "é possível afirmar que, de fato, ainda não se enraizou na experiência comum da sociedade brasileira um entendimento do bem coletivo que prescinda da ética proposta pelo cristianismo".

Nos últimos anos o que temos visto é o crescimento cada vez maior do número de políticos ligados de forma declarada à religiosidade cristã. Não nos referimos a casos isolados de religiosos eleitos ao longo da (frágil) história da democracia brasileira, mas sim da "explosão" dos evangélicos na política (Freston, 1992), sobretudo membros de igrejas (neo)pentecostais ${ }^{6}$. O fenômeno data da década de 1980, e por conta da atuação de vereadores(as), prefeitos(as), governadores(as), mas sobretudo de deputados(as) e senadores(as), o campo da política continua sendo incapaz de ignorar as mediações da religião.

Em voga estão: 0 aumento de candidaturas de líderes de igrejas católicas e (neo)pentecostais, líderes esses que expõem abertamente suas filiações e interesses religiosos e, dessa forma, veem nos púlpitos das igrejas locais privilegiados para fazer campanhas eleitorais; 0 ativismo político (neo)pentecostal como forma de "lutar" contra os avanços e o poder da lgreja Católica e a favor da defesa de interesses das próprias igrejas evangélicas; as alianças protagonizadas por evangélicos nos

5 Isso não significa que não havia restrições no Código Civil de 1917 às igrejas. Não nos cabe aqui esmiuçar os textos da lei e suas implicações para as instituições religiosas. Também não queremos dizer que a religião, com a declaração de um Estado laico, não esteve (e está) isenta de restrições.

6 A opção pela grafia "(neo)pentecostais" é para englobar em um mesmo termo os membros tanto de igrejas pentecostais quanto de igrejas neopentecostais. Para mais informações sobre essa questão indicamos a leitura de Guimarães (2016). 
poderes executivo, legislativo e judiciário; o discurso de um ideal "moral" para a sociedade brasileira que precisa ser recuperado, uma vez que a sociedade está "perdida" (aqui a maioria das reivindicações são contra pautas sobre aborto, drogas, ensino em escolas públicas e políticas afirmativas em prol de direitos de LGBTQ); e, não menos importante, a polarização e os discursos de ódio em plataformas midiáticas on-line entre grupos "contra" e "a favor" de tudo o que acabamos de descrever e de tantas outras ações provenientes da inserção direta de evangélicos na política.

A fim de exemplificar o cenário que trazemos à tona, relembramos a fala do deputado federal Diego Garcia (PHS) em ocasião de um seminário a favor da vida (contra o aborto em quaisquer situações) na Câmara dos Deputados. Durante sua fala no evento, o deputado declarou que "constantemente tentam colocar em matérias do plenário 'jabutis'7 que atentam contra a vida, que se levantam contra a família. Temos vigiado muito" (Fernandes, 2016). Garcia se refere aos seus opositores do âmbito legislativo e deixa claro que está atento a propostas com o objetivo de aprovar na Câmara tudo o que, segundo sua visão pessoal, religiosa e do grupo político que representa, atente contra a moral da sociedade brasileira.

Diego Garcia é membro da Frente Parlamentar Evangélica (FPE), mesma Frente de figuras públicas polêmicas como o pastor e deputado Marco Feliciano (PSC), o deputado Jair Bolsonaro (PSC), o deputado Eduardo Bolsonaro (PSC) e 0 senador Magno Malta (PR). (Auto)classificados como conservadores e de direita, os parlamentares da FPE são acusados de utilizar a Bíblia, cânone do cristianismo, na execução dos seus mandatos e na legislação do país (Vital; Lopes, 2013). Em Brasília, o grupo possui forças suficientes para se articular e se posicionar contra projetos de lei acerca de gênero, casamento entre pessoas do mesmo sexo, direitos de pessoas LGBTQ, aborto, descriminalização da maconha, constituição da família, entre outros.

As Frentes Parlamentares (FP) são as uniões de representantes dos poderes legislativos em torno de temas específicos. No âmbito federal ${ }^{8}$, o princípio de formação das FP se deu em ocasião da Assembleia Nacional Constituinte que redigiu a Constituição de 1988, carta magna do Brasil. Mesmo que de modo informal, um grupo de deputados ligados a questões rurais se uniu, à época, com o objetivo de redigir algumas partes da Constituição e, articulados, fazer frente a posições contrárias às da agroindústria. Em 1997, a Câmara dos Deputados (CD) já possuía doze desses grupos.

Desde o início, as FP são chamadas de "bancadas", mas há de se destacar algumas diferenças entre esses termos. Uma bancada é, na verdade, uma associação de deputados de uma mesma representação partidária sem que isso acarrete atribuições legais frutos dessa associação. Por sua vez, as FP são grupos compostos por deputados e senadores de partidos distintos com interesses semelhantes em torno de determinados assuntos.

Ademais, uma FP precisa cumprir uma série de requisitos para que seja instaurada e, dessa forma, reconhecida como grupo capaz de lidar com determinadas questões nos trâmites da Casa ${ }^{9}$. Segundo o Art. $2^{\circ}$ do Ato n 69 , de 11 de novembro de 2005, responsável por criar o registro de FP, "considera-se Frente Parlamentar a associação suprapartidária de pelo menos um terço de membros do Poder Legislativo Federal, destinada a promover o aprimoramento da legislação federal sobre determinado setor da sociedade". Em outras palavras, desde 2005 um grupo de políticos organizados em prol de um tema fica responsável por "aperfeiçoar os processos legislativos" desse tema visto que possui um número maior ou igual a 171 deputados filiados ${ }^{10}$.

\footnotetext{
7 "Jubuti" é o termo dado a quaisquer emendas em votações no plenário

8 As FP não são uma exclusividade do legislativo federal. Há formação de FP nos legislativos estaduais e municipais. Para a realização dessa pesquisa, consideramos apenas as FP do legislativo federal.

9 Segundo Duarte (2012), "Casa" é uma expressão nativa utilizada para se referir tanto à Câmara dos Deputados quanto ao Congresso Nacional - as duas Casas (Duarte, 2012). 100 cálculo considera uma legislatura com 513 deputados e deputadas.
} 
A FPE foi criada no dia 18 de setembro de 2003 na 52를 legislatura (2003-2006). Segundo Baptista (2009) e Duarte (2012), a instauração se deu em uma sessão solene do Congresso Nacional em homenagem ao dia nacional de missões evangélicas. 0 presidente da sessão, deputado Pedro Ribeiro (PR), apresentou o deputado Adelor Vieira (PMDB) como o primeiro presidente da FPE e os demais membros da diretoria composta, em sua maioria, por deputados filiados à Assembleia de Deus, igreja de denominação pentecostal. Hoje, na 55a legislatura (2015-2018) a FPE possui 199 deputados e quatro senadores filiados sob a presidência do deputado João Campos (PRB).

As estratégias e posições adotadas pela FPE no ato de instauração da Frente como entidade jurídica do Congresso Nacional são semelhantes às adotadas nos dias de hoje, com o adendo que, legislatura após legislatura, o número de membros e as inserções de preceitos religiosos nos assuntos da Casa são cada vez mais fortes. 0 pluripartidarismo com o objetivo de ampliar uma rede forte para alcançar seus objetivos é uma estratégia da FPE observada por Baptista (2009) e Duarte (2012). Segundo os autores, as principais iniciativas da FPE estão concentradas em ações em defesa da "família, da moral e dos bons costumes" de acordo com crenças religiosas cristãs.

Dito isso, o histórico dos modos de se fazer política em nosso país e a influência e atuação da FPE são fatos capazes de colocar em xeque a frase de abertura deste texto: o Brasil é um país laico. Cremos que o mais correto a se dizer é que no Brasil existe uma definição de laicidade que está em constante disputa entre grupos. Logo, para embasar a nossa reflexão e a análise a seguir, vamos ao encontro de um evento já consolidado no Brasil e que tende a nos dizer bastante sobre a luta por direitos de minorias em um país laico e sobre as mediações do religioso na política: a Parada do Orgulho LGBT de São Paulo.

\section{PARADA LGBT E DEMANDAS MORAIS POR JUSTIÇA}

Nas últimas cinco décadas é possível listar vários avanços com relação a essas lutas por conquistas de direitos e reconhecimento. A orientação homossexual foi descriminalizada e deixou de ser vista como uma doença em vários países, a união civil entre pessoas LGBTQ é aceita e há permissão legal para a adoção de filhos por casais homoafetivos. Todavia, sobretudo em um país marcado pela (intensa) mediação da religião na política como o nosso, a luta ainda é grande de acordo com os militantes.

Sobre as Paradas do Orgulho LGBT de São Paulo, a primeira edição do evento ocorreu em 1997 e a cada ano o número de militantes e simpatizantes aumenta. Segundo dados divulgados pela ONG organizadora, a Associação da Parada do Orgulho LGBT (APOGLBT), a primeira edição do evento contou com cerca de duas mil pessoas. Em 2017 o número chegou ao recorde de três milhões de pessoas em plena Avenida Paulista"1. Todavia, a organização do evento destaca que o clima de festa e confraternização entre militantes e apoiadores da causa LGBTQ não pode abafar o caráter de protesto e de luta. Além da Parada em si, evento de maior destaque, uma série de reuniões, seminários, feiras, debates, ciclos de palestras e mostras artísticas são realizados durante o ano no intuito de fortalecer a causa e unir LGBTQ de todo o Brasil.

0 tema escolhido pela organização do evento em 2017 foi: "Independente de nossas crenças, nenhuma religião é lei! Todas e todos por um Estado laico". De acordo com fontes oficiais ligadas à organização da 21ª Parada do Orgulho LGBT, a escolha

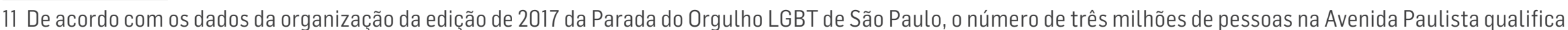

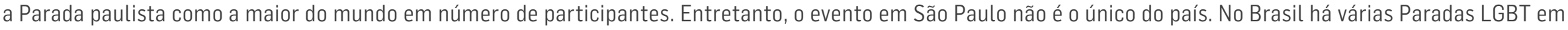
diferentes estados ao longo do ano, menores em número de participantes. 
do tema surgiu de reuniões feitas com ONG, coletivos e militantes. Nessas reuniões, o que impulsionou a decisão pelo tema foi a questão do fundamentalismo religioso que tem ganhado cada vez mais espaço dentro da política aliada aos retrocessos morais acerca de assuntos ligados à diversidade em um país que é, em teoria, laico. No site oficial da APOGLBT, a presidenta da associação, Cláudia Regina, declara que:

É uma grave ameaça à cidadania, e à democracia constitucional brasileira, o fato de integrantes dos três poderes, em qualquer nível, atuar tendo como guia seus valores religiosos, sem observância à cidadania, à pluralidade e aos direitos humanos. Cargos públicos não podem ser utilizados para imposição de visões religiosas quaisquer sejam elas. [...] Dentre as diversas vítimas do desrespeito ao Estado laico, estamos nós LGBT. Os exemplos são inúmeros e desumanos. ${ }^{12}$

Cláudia Regina se refere, entre outras coisas, a projetos de leis criados e votados por deputados da FPE que são contrários a pautas LGBTQ. Em meados de 2013, por exemplo, um debate travado por lideranças evangélicas de um lado, e ativistas de direitos humanos a favor da diversidade sexual de outro, ganhou amplo espaço na mídia. Sob o comando de Marco Feliciano, a Comissão de Direitos Humanos e Minorias (CDHM) da Câmara aprovou no dia 18 de junho de 2013 um projeto que conferia aos psicólogos o direito e o respaldo legal de promover tratamentos em seus pacientes com o objetivo de reverter a orientação homossexual, caso fosse de interesse do próprio paciente. A proposta ficou conhecida como "cura gay" e o resultado da votação realizada pela CDHM foi considerado, a contragosto de muitas pessoas, uma vitória da FPE, que tentava avançar com o projeto há dois anos.

Outro exemplo de projeto de lei encabeçado pela FPE e contrário a pautas LGBTQ de diversidade e direitos humanos é 0 Estatuto da Família. O Projeto de Lei no 6.583 de 16 de outubro de 2013, criado pelo deputado federal e membro da FPE, Anderson Ferreira (PR), dispõe sobre os direitos das famílias brasileiras e demais diretrizes de políticas públicas voltadas para a valorização do núcleo familiar. Em suma, o projeto surgiu para (tentar) definir o que é uma família no Brasil, ou seja, para criar uma série de regras capazes de dar ou de retirar de relações afetivas o título de "família". No projeto lemos: "define-se entidade familiar como o núcleo social formado a partir da união entre um homem e uma mulher, por meio de casamento ou união estável, ou ainda por comunidade formada por qualquer dos pais e seus descendentes" (BRASIL, 2013). A intenção por trás desse projeto é classificar como família apenas uniões heterossexuais e monogâmicas, além de coibir a adoção de crianças por casais homossexuais.

Por fim - e somente a título de exemplo, pois poderíamos relatar mais casos - há a forte objeção da FPE ao projeto de distribuição de materiais com discussões acerca de gênero (sexual) para educadores de escolas públicas do país. Em 2004, 0 governo federal criou o programa Brasil sem Homofobia a fim de combater o preconceito contra pessoas LGBTQ. Como parte do programa, a formação de professores estava incluída, pois acreditava-se que o respeito precisava ser ensinado desde cedo nas escolas. Contudo, o material, apelidado de forma pejorativa como "kit gay", foi impedido de ser distribuído por membros da FPE que já possuíam força e articulações suficientes no Congresso. Em carta aberta, o deputado Marco Feliciano alegou que o "kit gay" estimulava o "homossexualismo" e a promiscuidade entre as crianças.

Dentro e fora de instituições oficiais da política, todo esse cenário sistematizado até aqui convoca uma série de atores para uma disputa de sentidos em torno da própria definição de laicidade e de diversidade no Brasil. A questão que se coloca é: como se dão as interações e as disputas de sentido em torno da relação entre religião e política? Objetivamos captar os sentidos e compreender quais são as concepções (argumentos, perspectivas) trazidas à tona por esses públicos que dão contornos aos embates na internet.

12 Disponível em: $<$ https://goo.gl/as9f4i >. Acesso em: 28 jun. 2016. 
Sabemos que, em um processo ampliado de debate on-line (articulando várias esferas públicas de discussão), as dinâmicas comunicativas tendem a se dar de forma integrada, mas nem sempre coordenada e simultânea. Sob esse aspecto, as redes sociais permitem uma estrutura de conversação on-line que congrega um público de públicos atuando a partir de diferentes espaços e temporalidades.

Partimos do pressuposto de que o processo ético de debate on-line é formado pela interconexão entre diferentes contextos comunicativos, os quais reúnem diferentes atores e seus modos de comunicação específicos; e de que a conversação política é uma atividade que envolve o enfrentamento público dos argumentos morais resultantes desses múltiplos contextos (Altheman; Martino; Marques, 2016; Oliveira; Sarmento; Mendonça, 2014; Sarmento; Mendonça, 2016).

É importante ter cuidado com o pressuposto da mútua afetação e influência entre esferas ou âmbitos comunicativos que integram o processo de debate on-line. A ideia de que mudanças que se processam em determinados contextos necessariamente repercutem em outros deve ser questionada. 0 foco deve ser nas trocas comunicativas e conversações construídas em diferentes arenas com o propósito não só de articular discursos e atores, mas de revelar como tais discursos e atores, a partir da individualidade de suas experiências e relatos, conseguem produzir tais articulações. Por isso, o enfoque analítico das conversações pode ser mais interessante se procurar revelar como os conflitos, dissensos, formas de autoexpressão e expressão coletiva são trabalhados na interação (Eveland; Morey; Hutchens, 2011).

Mendonça e Amaral (2016) mostram que o potencial ético das trocas comunicativas realizadas nas redes sociais digitais está ligado às imbricações entre agenciamentos subjetivos e intersubjetivos, nas formas de engajamento pessoal e coletivo, nos modos de exposição a opiniões contrárias e nas possibilidades de questionamento de ordens discursivas estabelecidas e estanques.

A nosso ver, a potência política dos enunciados e dos modos de enunciação proporcionados pelo Facebook não se encontra exclusivamente em tentativas individuais e personificadas de questionamento de opressões e injustiças (por mais importantes que elas sejam dentro da ampliação de um entendimento de formas de participação política hoje), muito menos restrita ao choque de perspectivas diferentes.

Argumentamos a favor de uma potência política das conversações on-line que deriva não só das possibilidades enunciativas proporcionadas pelo Facebook, por exemplo, mas também de uma compreensão desse espaço como capaz de promover um pertencimento de grupo em que semelhantes pontos de vista e experiências possam encontrar-se e ter maior chance de tematizarem problemas e alcançarem publicidade (Conroy; Feezell; Guerrero, 2012).

Especificamente sobre o Facebook, nosso objeto de análise, José van Dijck (2012, p. 173) se mostra extremamente cautelosa em afirmar que esse espaço seria uma nova esfera pública ou mesmo uma expansão da esfera privada, exatamente por causa de seu caráter corporativista, que envolve estratégias complexas de publicidade, e sua própria concepção empresarial que visa o lucro:

Os estágios iniciais dessa luta [novo espaço de comunicação pública versus fluxo de controle da informação] estão articulados na maneira como Facebook molda a sociabilidade ao mesmo tempo e pelos mesmos meios que é moldado por fatores sociopolíticos, códigos legais e forças de mercado. Esta batalha por dominação está longe de ser concluída e provavelmente não terminará por muito tempo. 
Por outro lado, Mendonça e Amaral (2016) revelam, em pesquisa sobre o provimento de razões em espaços on-line em torno da questão LGBT, que o Facebook mostrou-se como um dos espaços em que as justificativas mais aparecem nos proferimentos, perdendo apenas para os fóruns institucionalmente constituídos (espaços on-line criados pelo governo para debater algum assunto que está em discussão nas esferas políticas), cujas características são dominadas pelo posicionamento político, 0 que explica 0 alto índice de justificativas (86,49\%).

No Facebook, 76,27\% das postagens nessa pesquisa apresentam justificativas, demonstrando que essa plataforma pode apresentar potenciais de debate político, dependendo da abordagem e do assunto. Com relação à configuração das trocas, podemos destacar o fato de que o próprio espaço do Facebook oferece ferramentas para a construção da conversação, e, ao mesmo tempo, aqueles que aí interagem constroem e se apropriam do contexto por elas gerado, aproveitando a experiência que já possuem de exploração da plataforma (Halpem; Gibss, 2013).

No Facebook, e em outros ambientes sociais da rede, há uma forte interseção entre o ambiente e as possibilidades de mediação que ele oferece: articulação com outras redes sociais, mecanismos de busca, citação e indexação (o que amplia as possibilidades de fundamentação e exemplificação de pontos de vista e argumentos, por exemplo). Tal característica é importante, pois não se pode desconsiderar que as trocas discursivas que acontecem em uma rede social frequentemente se espraiam para outras plataformas, dando origem a uma interconexão de esferas e de conteúdos.

A persistência, a possibilidade de responder a qualquer mensagem (postada de maneira síncrona ou assíncrona) e o arquivamento das trocas permitem que os enunciados não só sejam facilmente recuperáveis, como também tracem as diferentes conexões que realizam dentro e para além do espaço no qual foram postados.

Nesse sentido, como apontam Oliveira, Sarmento e Mendonça (2014, p. 59), o potencial ético e político de conversações realizadas nas redes sociais apresenta uma de suas dimensões quando nos dedicamos a entender os caminhos argumentativos construídos nas trocas, além de identificar crenças, valores e enquadramentos a partir dos quais os usuários expõem e negociam sentidos.

Tal constatação nos leva a perceber a importância de uma análise apurada dos contextos enunciativos de trocas on-line diante de questões morais de justiça. Além disso, não se pode tecer uma análise dessas trocas sem levar em consideração que grande parte delas é marcada pela hostilidade, pela desvalorização dos interlocutores e seus argumentos, pelas assimetrias de status entre os participantes e, sobretudo, pela não tematização de injustiças referentes ao próprio reconhecimento dos parceiros como moralmente dignos de serem vistos como interlocutores, como "pares".

Assim, o percurso metodológico por nós desenvolvido leva em conta que um processo de debate não se apresenta de maneira pontual, mas se desdobra em diferentes momentos no ambiente de conversação on-line.

\section{DEFINIÇÕES METODOLÓGICAS: DISPUTAS DE SENTIDO EM TORNO DA NOÇÃO DE LAICIDADE E DE DIVERSIDADE}

O espaço escolhido para apreender essa disputa de sentidos em torno de um estado laico (secular) e tudo o que é reivindicado por ambas as partes são as plataformas midiáticas on-line. Interessa para nós instâncias ordinárias do cotidiano da vida das pessoas nos quais cidadãos e cidadãs comuns, longe de esferas públicas oficiais, são convocados a dar opiniões diversas sobre determinados assuntos (Gillespie, 2010), entre eles o próprio tema da Parada do Orgulho LGBT de 2018: "Independente [sic] de nossas crenças, nenhuma religião é lei! Todas e todos por um Estado laico". 
Dito isso, selecionamos o Facebook como a plataforma midiática on-line a ser analisada e, de modo específico, os comentários postados na página do jornal Folha de S.Pauloacerca da notícia "Parada LGBT de São Paulo terá protestos contra a interferência religiosa", postada às 8h55min do próprio dia do evento (domingo, 18 de junho de 2017). Com os comentários em mãos, com as conversações que eles são capazes de gerar, é possível apreender os sentidos evocados pelo tema da 21ª Parada do Orgulho LGBT colocado em debate pela notícia do jornal.

O primeiro passo metodológico foi a coleta de todos os comentários da notícia selecionada por meio do programa OpSocial. 0 programa, disponível on-line, aglutina os comentários em uma tabela em ordem cronológica e os divide entre "comentários" e "respostas a comentários", além de fornecer dados como data, hora e link para o perfil da pessoa que escreveu cada texto. O segundo passo, após a coleta do material a ser analisado, é o processo de garimpo realizado com o auxílio do software NVivo, que nos fornece uma lista de palavras com maior incidência em todo o conjunto de comentários.

Feito isso, obtemos, a partir do tema trabalhado na notícia do jornal Folha de S. Paulo, os termos e expressões mais problematizadas pelos usuários e usuárias. 0 passo seguinte, antes da análise em si, é excluir, por meio do próprio software NVivo, os comentários que não são contemplados com os termos e expressões mais problematizados. Logo, temos em mãos para leitura e análises individuais um conjunto de comentários que carrega consigo vozes dissonantes com o objetivo de (des)estabilizar discursos ora predominantes na FPE, ora predominantes na comunidade LGBT.

No total, lemos 991 comentários selecionados após o filtro metodológico, todos suscitados pela notícia acerca da Parada LGBT postada na página do jornal Folha de S.Paulo no Facebook. O processo interativo entre os usuários ocorre através de comentários e de respostas aos comentários, o que denominamos de interação direta. Todavia, há uma série de comentários sem resposta (sem interação direta), mas que não estão desprendidos do contexto mais amplo de debate em torno da notícia.

Assim se configura a dinâmica de postagens e interação em plataformas midiáticas, sobretudo os espaços de comentários de publicações no Facebook. De antemão, sabemos que a opinião pública é espraiada e captá-la é uma tarefa que ultrapassa os limites de página do nosso texto e não se reduz (apenas) aos comentários de uma única notícia. Por meio do nosso recorte, pretendemos entender parte do que é posto em jogo em interações digitais a partir do momento que os interesses LGBTQ são reivindicados.

Observamos, a partir das trocas desencadeadas pela referida notícia, como os interlocutores procuravam definir os termos capazes de abordar o problema; como buscaram compreender as principais nuances da questão; o modo como se deu a apropriação e a contestação crítica dos pontos de vista publicamente disponíveis; e como ocorreu a explicitação das premissas que sustentam pontos de vista, configurando uma dimensão ética e moral de relação com a alteridade.

Para melhor organizar e apresentar nossas reflexões, estabelecemos três eixos analíticos principais, ressaltando suas relações com parâmetros éticos e morais de avaliação reflexiva: 
Quadro 1: Eixos analíticos

\begin{tabular}{|c|c|c|c|}
\hline Eixo de análise & Definição & Aspectos éticos & Aspectos morais \\
\hline $\begin{array}{c}\text { Posicionamento } \\
\text { dos interlocutores } \\
\text { através de marcadores } \\
\text { identitários }\end{array}$ & $\begin{array}{l}\text { Os interlocutores procuram } \\
\text { identificar modos de abordar } \\
\text { o problema em pauta a partir } \\
\text { de pistas relacionadas às } \\
\text { fronteiras entre "nós" e "eles". } \\
\text { Presença de uma "política } \\
\text { da identidade". Dificuldade } \\
\text { de haver respeito mútuo. }\end{array}$ & $\begin{array}{l}\text { Produção de argumentos } \\
\text { e pontos de vista voltados } \\
\text { para o reforço de identidades } \\
\text { socialmente construídas } \\
\text { (fixam os atores em posições) } \\
\text { e tendência a avaliar o } \\
\text { problema unicamente do } \\
\text { ponto de vista individual } \\
\text { e restrito ao grupo. }\end{array}$ & $\begin{array}{l}\text { Dificuldade de negociar } \\
\text { e alcançar um horizonte } \\
\text { moral partilhado que sirva } \\
\text { como parâmetro coletivo } \\
\text { de justiça social para a } \\
\text { avaliação crítica aberta, } \\
\text { respeitosa e coletiva do } \\
\text { problema em pauta. Ausência } \\
\text { de quadros interpretativos } \\
\text { compartilhados. }\end{array}$ \\
\hline $\begin{array}{l}\text { Explicitação de } \\
\text { premissas que } \\
\text { sustentam as } \\
\text { considerações e } \\
\text { argumentos trocados }\end{array}$ & $\begin{array}{l}\text { Os interlocutores tentam } \\
\text { apresentar justificativas para } \\
\text { embasar suas considerações } \\
\text { diante de outros que deles } \\
\text { discordam. Agrupamento } \\
\text { e polarização de razões e } \\
\text { crenças não negociáveis. }\end{array}$ & $\begin{array}{l}\text { Cada interlocutor formula } \\
\text { e oferece suas razões aos } \\
\text { outros, o que pode ser feito } \\
\text { de maneira irônica, agressiva, } \\
\text { respeitosa etc. Modos de } \\
\text { consideração da diferença } \\
\text { presentes na apreciação ou } \\
\text { depreciação da opinião alheia. }\end{array}$ & $\begin{array}{l}\text { Componente de reflexividade } \\
\text { necessária à produção da } \\
\text { justiça: o quão abertos os } \\
\text { interlocutores estão para } \\
\text { acolher, escutar e considerar } \\
\text { a fala alheia, reconfigurando } \\
\text { seu próprio modo de pensar } \\
\text { diante de contestações à sua } \\
\text { forma de ver e agir no mundo. }\end{array}$ \\
\hline $\begin{array}{c}\text { Negociação de } \\
\text { parâmetros de justiça }\end{array}$ & $\begin{array}{l}\text { Oscilações entre o que se } \\
\text { apresenta como justo e bom } \\
\text { para sujeitos e grupos e o que } \\
\text { pode ser justo e bom para a } \\
\text { coletividade. Dificuldade em } \\
\text { "colocar-se no lugar do outro". }\end{array}$ & $\begin{array}{c}\text { Personalização e } \\
\text { individualização dos } \\
\text { parâmetros que definem } \\
\text { concepções de justiça. } \\
\text { Tendência a associar justiça } \\
\text { à punição estabelecida a } \\
\text { partir de critérios subjetivos. }\end{array}$ & $\begin{array}{l}\text { Conhecimento das leis que } \\
\text { estabelecem parâmetros } \\
\text { iguais de expressão e proteção } \\
\text { às liberdades individuais, mas } \\
\text { dificuldade em aplicá-las. } \\
\text { Predomínio dos moralismos. }\end{array}$ \\
\hline
\end{tabular}

Fonte: Elaborado pelos autores.

\section{Definição do problema e posicionamento dos interlocutores a partir da demarcação identitária}

Nossa análise não se prendeu apenas a uma análise do conteúdo dos comentários e das trocas, mas procuramos ver como determinados discursos e ideologias ganham forma e como se relacionam com discursos sociais mais amplos (Witschge, 2008). Sabemos que as considerações tecidas pelos atores sociais em debate se articulam com uma série de perspectivas, experiências e modos de expressão que não podem ser desconsiderados. Assim, os comentários por nós analisados são considerações informadas pelas identidades e interesses dos participantes, que reafirmam e negociam constantemente suas diferenças, movendo e redesenhando relações de poder e forças de opressão. 
A dinâmica de comentários e respostas em plataformas midiáticas on-line sobre um tema tão polêmico faz das interações um processo em que identidades sociais bem marcadas e pouco porosas à diferença prevaleçam. Comentários e respostas ${ }^{13}$ relativos à identificação do pertencimento dos interlocutores a determinado gênero e/ou religião são guiados por afirmações acerca do que participantes individuais tomam como afirmação de sua própria identidade pessoal em relação ao sentido do grupo e à afinidade com outros membros do grupo.

Na tentativa de definição inicial da questão que envolve grupos LGBTQ e grupos religiosos, há nos comentários uma tentativa de encorajar a solidariedade entre aqueles que possuem afinidade. "Essa política cultural de produção de solidariedade consiste na afirmação da especificidade e da diferença diante de um público amplo de quem o movimento espera respeito e reconhecimento de suas ações e virtudes" (Young, 2000, p. 103). 0 encastelamento das diferenças tende a dificultar negociações e a fazer com que os interlocutores se agrupem e polarizem seus entendimentos e opiniões em torno do que consideram como alinhados a "nós", contra a estranheza que os fazem repudiar o "eles".

Há uma generalização nos comentários que classifica cristãos como fundamentalistas e LGBTQ como promíscuos. As argumentações são construídas com base em crenças, valores e normas partilhadas entre grupos específicos (religiosos de um lado e LGBTQ de outro) que não são negociadas, mas sim generalizadas e reafirmadas em discursos de ódio sob a máscara de liberdade de expressão, como na interação entre A e B:

Para que serve a parada gay? Ver as homofóbicas que não tem coragem de se assumir dando piti. (A)

A LGBT não passa de um bando de narcisistas, exibicionistas imbecis, nojentos e indecorosos, não aceitamos essas imoralidades, perversidades e a falta de respeito com a sociedade que valoriza a família. (B)

Falas como essas são recorrentes ao longo do conjunto de comentários analisados. Como veremos adiante, há premissas religiosas que sustentam essas definições de posições identitárias e muitas delas pautadas por uma visão histórica de que 0 cristianismo faz parte de uma identidade nacional (Karnal, 2017). Assim, se for para combater uma identidade e uma religião, que sejam aquelas que não definem um "nós".

A insistência de alguns de que a luta das minorias LGBTQ, desfavorecidas pelos modos de se fazer política da FPE, é legitima e necessária esbarra, mais uma vez, em discursos impregnados de uma concepção religiosa austera, como o comentário de C.

O que veremos na tal parada é o de sempre, furtos, roubos, depredações, violência, bebedeiras, drogas, atentando violento ao pudor, corpos deformados (aliás, tudo isso acontece no carnaval também), o duro é depois que acabar a zorra, a purpurina, o efeito das drogas e do álcool, ir para a casa se olhar no espelho e não saber quem é, pois não são homens tampouco mulheres, não possuem definição na Criação. (C)

Nesses comentários percebemos como as identificações identitárias fechadas são embasadas em uma concepção específica de moral (religiosa), a ponto de equiparar tudo aquilo que é considerado nocivo e pernicioso dentro de um determinado quadro moral valorativo: drogas, álcool, homoafetividade, carnaval, violências etc.; os públicos que frequentam a Parada Gay são homogeneizados e apontados com severo e condenatório julgamento. Não há escuta, mas simplesmente embates e defesas de posicionamentos fechados, avaliados e validados em si mesmos, sem uma atenção para a alteridade e suas diferenças. E isso ocorre em ambos os lados.

13 As transcrições dos comentários são feitas de modo literal e com respeito à grafia utilizada pelos próprios autores e autoras. Não suprimimos, corrigimos ou censuramos termos, erros de português ou estruturas frasais. Todavia, suprimimos as identidades das pessoas. 
Em um debate on-line, a extrema polarização entre os interlocutores dificulta a construção do respeito mútuo ${ }^{14}$ e do reconhecimento do valor do outro como parceiro moralmente válido de debate (Maia; Rezende, 2016; Witschge, 2008). Empenhados na produção de enunciados que reiteram relações sociais desiguais, discriminatórias e opressoras, os pares em disputa relutam em abrir-se às experiências, narrativas ou contribuições que thes soam estrangeiras: cada parte percebe a si mesma como autossuficiente em suas crenças, modos de julgar e avaliar condutas, questões e ações (Grahan; Witschge, 2003).

Segundo Witschge (2011), os desacordos morais e as avaliações éticas dos sujeitos deveriam promover a receptividade dos participantes à diferença e não a negação de sua legitimidade para participar no debate e até mesmo para "existir". Contudo, percebemos que apesar de vozes dissonantes e dissensuais terem acesso formal às redes sociais digitais, isso não significa que os interlocutores alteram suas percepções e entendimentos acerca dos universos de sentido diferenciados que caracterizam a alteridade radical.

Vozes discordantes são oferecidas ao debate (sob a constante ameaça de ataque, humilhação, injúria e aversão), mas sua transformação em fala política depende de um gesto de acol himento dos demais participantes. E, como destacado por Witschge, como estabelecer interações significativamente reflexivas (capazes de alterar os posicionamentos dos participantes) à luz de diferenças irreconciliáveis? Este nos parece ser um dos principais dilemas éticos que atravessam as democracias contemporâneas.

\section{Explicitação das premissas que sustentam os pontos de vista trocados}

Já no momento de estabelecimento das fronteiras entre o "nós" e o "eles", é possível perceber uma busca constante de elementos discursivos específicos capazes de fortalecer crenças individuais e restritas a grupos, tornando-as ainda mais impermeáveis aos ataques alheios. 0 princípio da laicidade é utilizado como premissa legitimadora de discursos de ódio, ou seja, em nome da laicidade alguns religiosos fundamentalistas se veem investidos da "missão" de defender a incolumidade do seu direito de liberdade de expressão religiosa sem se importar se isso interfere no direito de outra pessoa de escolher viver a sexualidade conforme bem entender. De todos os comentários lidos, o com o maior número de "likes" (curtidas) é:

Nunca vi LGBT protestar frente a uma mesquita muçulmana, será porque? (D)

Porque $87 \%$ do Brasil se considera cristão, e nós temos uma bancada evangélica ultrarreacionária que quer acabar com a neutralidade religiosa do estado. Eu não vejo nenhum muçulmano na câmara querendo acabar com os direitos civis de ninguém! (E)

O comentário $\mathrm{D}$, que além de mais curtido é um dos que possui mais interações diretas, reflete o desejo da pessoa que o escreveu de desviar o foco da intolerância praticada pela FPE contra pessoas LGBT para outra religião que também é reconhecida por sua intolerância, mas que pratica ações de extermínio explícitas.

Devido aos modos como grupos terroristas islâmicos rejeitam veementemente a orientação homossexual por ser contrária aos desígnios de Alá previstos no Alcorão e, sobretudo, como homossexuais são assassinados em países do Oriente Médio, o comentário expressa que a real religião que deve ser combatida é a religião do homicídio público (o islamismo), e não 0 cristianismo da FPE. 0 teor do comentário considera que os valores cristãos presentes na política não são dignos de protesto, pois os verdadeiros grupos radicais não são os inimigos declarados pela organização do evento.

14 Para Maia e Rezende (2016, p.123), "o respeito mútuo dirigido a um parceiro de interação é diferente do acesso cognitivo a opiniões, valores e interesses. As pessoas, mesmo respeitando umas às outras como interlocutores moralmente válidos podem reconhecer diferenças de visão ou posições que podem ou não ser respeitáveis". Assim, o respeito por outras pessoas envolveria um conjunto de disposições para agir e impedi-las de agir, a fim de reconhecê-las ou não como agentes moralmente competentes, aptos a produzirem justificativas para seus proferimentos e de negociá-las publicamente. 
Não se trata aqui de se colocar no lugar do outro para debater sobre as diferentes visões de mundo em conflito, mas de marcar posições e territórios que entrincheiram suas fronteiras com mais e mais vigor. A resposta que E oferece a $D$ pauta-se na ideia de que o protesto da 21a edição da Parada do Orgulho LGBT se dá, sobretudo, pelas ações de uma Frente evangélica que quer "acabar com os direitos civis" de homossexuais. Em outras palavras, E chama a atenção de D e das demais pessoas envolvidas na interação para o contexto político brasileiro que não possui uma bancada mulçumana e, logo, não teria motivos para protestar em frente a um templo mulçumano.

Outra desculpa pra atacar os cristãos, o país afundando em corrupção e eles vão protestar contra uma coisa que já existe, o Estado é laico mas não é ateu, nossa constituição garante liberdade religiosa! (F)

Já dissemos aqui que, no processo da implantação da (difusa) laicidade no Brasil, a Igreja Católica, religião dominante, se envolveu em intensos embates com o Estado a fim de garantir o princípio da "liberdade religiosa" para quaisquer religiões, pois o que estava em jogo era uma autonomia jurídica das associações religiosas, sobretudo as cristãs. Nesse bojo, com tal autonomia veio o "consenso" de que a liberdade de expressão de crença é irrestrita e incondicionada aos direitos de outras pessoas não adeptas a essas crenças.

Assim, os pressupostos que sustentam as trocas analisadas revelam muitos obstáculos à promoção da reflexividade, ou seja, a disposição em revisar os próprios entendimentos, preferências, interesses e convicções por meio de um processo dialógico de troca de opiniões. Negociar através das diferenças significa buscar a valorização das capacidades específicas dos indivíduos; reconhecer que todos possuem habilidades para aprender e melhorar seu potencial; incluir todas as perspectivas sem prejudicar o outro, seja através do desrespeito, seja por meio de preconceitos e condenações éticas ou morais (Witschge, 2007, 2008, 2011).

\section{Negociação de parâmetros de justiça}

0 termo "laicidade" aparece no tema da 21a Parada do Orgulho LGBT de São Paulo como um princípio constitucional a ser respeitado - "Independente [sic] de nossas crenças, nenhuma religião é lei! Todas e todos por um Estado laico". Da mesma forma, o termo laicidade é evocado na fala de um grupo de pessoas que, contrários à pauta dos direitos civis de LGBTQ, atacaos de forma desrespeitosa a ponto de considerar que sim, é por meio da laicidade do Brasil que o país pode assumir uma postura religiosa avessa à diversidade sexual, pois o "Estado é laico, mas não é ateu". A fala de G endossa essa ambiguidade que acompanha o termo laicidade e a noção de liberdade religiosa e de expressão:

Interferência dos LGBTS nas religiões???? São eles que querem impedir o livre pensar! Querem impedir que cristãos vivam aquilo que acreditam???? (G)

Nas trocas analisadas não vemos definido um sentido de ação política que ganha corpo quando os interlocutores fazem demandas de justiça para a ampla sociedade. Pelo contrário: justiça aqui é desenhada a partir de parâmetros particulares e num sentido negativo, sem abertura à singularidade alheia e pautado pela imposição ao outro dos parâmetros éticos e morais que guiam as ações de um único grupo.

O comentário de $\mathrm{G}$ exemplifica isso ao mostrar uma pessoa que coloca sua cosmovisão religiosa acima dos direitos de outras pessoas (moralismo) e considera a luta de minorias LGBT uma ameaça ao "livre pensar" de cristãos. Importante destacar que a justificativa de que "o Estado não é ateu" não abre margem para diferentes credos religiosos se pronunciarem e construírem em conjunto de regras morais que definiriam uma justiça social mais abrangente. Há uma assimetria quando o assunto é reconhecer "a" religião do Estado que, em linhas gerais, deveria ser um Estado cristão sob o ponto de vista de muitos dos participantes. 
Logo, de modo geral, as interações nos comentários são pautadas pelo desrespeito e pela enorme dificuldade de colocar-se no lugar do outro, ou seja, a capacidade que os participantes desenvolvem de tomar a perspectiva do outro e, autorreflexivamente, perceberem-se por meio da perspectiva de uma segunda pessoa (Marques; Martino, 2016). Isso dependeria de uma sensibilidade recíproca à experiência alheia, ativada pela empatia, pela emoção e pelos sentimentos morais.

No espaço digital os corpos não são vistos, e o anonimato garante certa proteção para quem se propõe a interagir. Todavia, isso não significa que não haja emoção nas trocas de falas. Ao contrário, como nos comentários supracitados, os desafetos são exacerbados e o "outro" é sempre tomado como um inimigo que precisa ser calado, se não eliminado. Posto isso, o caráter da Parada LGBT de SP, que se propôs a ser um evento de protesto pacífico contra as ações de políticos pautados por preceitos religiosos em um país laico, toma outras proporções na internet ao passo que agrega as mais diferentes pessoas (e opiniões mais ou menos iguais) em um campo de batalha e disputas por sentidos que, em grande parte, não são negociados, apenas manifestados.

Dessa forma, o laico e o sagrado são categorias em constantes intersecções, mas em disputas; dicotômicas, porém indissociáveis; definidas, contudo polissêmicas. Os recortes e as escolhas dos comentários são para mostrar alguns padrões de discursos em plataformas midiáticas on-line, discursos esses capazes de evidenciar o quanto a noção de laicidade é permeada por características históricas de um país que se constituiu através de acordos e de benefícios entre religião e governo de modo que, até hoje, os limites de atuação do religioso na política não são claros.

Além disso, a questão da diversidade (sexual) é vista mais como um perigo do que como, tão somente, outros modos legítimos de ser. A tessitura do conjunto de comentários analisados, então, mostra um local de disputas de sentido através de interações mais interessadas em desprivilegiar os interesses e as causas de determinados grupos em contextos de pouca (quase nenhuma) abertura para diálogos sem ataques e ofensas.

\section{CONSIDERAÇÕES FINAIS}

Diante das declarações da presidenta da APOGLBT; dos exemplos de projetos de lei e dos modos de atuação da FPE, que de maneira oficial legisla de acordo com princípios morais e éticos de uma religião específica; e da retrospectiva do processo de constituição da laicidade no Brasil, é possível compreender que afirmar uma laicidade plena no Brasil, isto é, a separação entre religião e política, é difícil.

Montero (2013, p. 25) é enfática em dizer que "as normas legais não são transparentes nem sua aplicação é mecânica, um conjunto de percepções filtra a sua leitura e disputa seus significados". Em um país como o Brasil, que desde a sua formação republicana é marcado por (intensas) mediações do religioso na política, é de se esperar um cenário atual permeado por conflitos e jogos de interesses pessoais e de grupo em torno da laicidade dos limites dados à diversidade sexual. A análise dos comentários em uma rede social digital nos mostrou o quão intensos são esses conflitos e jogos de interesses.

Privilegiar esses espaços on-line para apreender as dinâmicas de interação entre grupos distintos é considerar espaços democráticos, agonísticos, nos quais corpos não são vistos e discursos (comentários) diversos são proferidos em uma espécie de arena pública capaz de revelar muito sobre o modo de pensar a questão da laicidade e o direito à diversidade em nosso país. Lembramos que um Estado laico garante a liberdade de crença, mas nenhuma crença deve ser sobreposta aos modos de vida de outra pessoa. Logo, a pauta levantada pela Parada do Orgulho LGBT de 2017 elucida que a relação entre laicidade e respeito a direitos individuais no Brasil é algo ainda não plenamente alcançado e que a luta diária não se dá apenas em instâncias políticas oficiais, mas também em discursos paralelos na internet. 
Ressaltamos ainda que as trocas on-line entre grupos polarizados estão sujeitas à ação de atores institucionais sob múltiplas influências, hábitos que desenvolvem, iniciativas que tomam e respostas dos públicos atingidos por leis e normas que almejam produzir justiça social. Grupos que agem com base em valores e afetos, preceitos éticos e morais muito específicos acabam promovendo indiferença, antipatia ou indignação, colocando as emoções, as ideologias e os constrangimentos de poder no centro dos dilemas éticos enfrentados. Para descrever o trabalho moral das instituições políticas, religiosas e sociais é preciso considerar tanto o desenho das tensões e problemas na esfera pública quanto as ações dos atores supostamente encarregados de regulá-los e solucioná-los.

\section{REFERÊNCIAS}

ALTHEMAN, Francine; MARTINO, Luís Mauro S.; MARQUES, Angela C. S. Conversações políticas no YouTube e suas contribuições para o processo deliberativo acerca do Projeto de Lei do Ato Médico. In: MENDONÇA, Ricardo F.; SAMPAIO, Rafael C.; BARROS, Samuel A. R. (Orgs.). Deliberação on-line no Brasili entre iniciativas de democracia digital e redes sociais de conversação. Salvador: EDUFBA, 2016. p. 272-299.

BAPTISTA, Saulo. Pentecostais e neopentecostais na política brasileira: um estudo sobre cultura política, Estado e atores coletivos religiosos no Brasil. São Paulo: Annablume; São Bernardo do Campo: Instituto Metodista Izabela Hendrix, 2009.

BRASIL. Constituição (1934). Constituição da República dos Estados Unidos do Brasil. Rio de Janeiro, 1934. Disponível em $<$ https://goo.gl/bXDyka>. Acesso em 6 mar. 2018.

BRASIL. Constituição (1988). Constituição da República Federativa do Brasil. Brasília, DF: Senado Federal/Centro Gráfico, 1988.

Câmara dos Deputados. Projeto de Lei no 6.583, de 16 de outubro de 2013. Dispõe sobre o Estatuto da Família e dá outras providências. Brasília, DF: Câmara dos Deputados, 2013.

CANCLINI, Néstor G. Culturas híbridas, poderes oblíquos. 4. ed. São Paulo: Edusp, 2015.

CONROY, Meredith; FEEZELL, Jessica T.; GUERRERO, Mario. Facebook and political engagement: a study of online political group membership and offline political engagement. Computers in Human Behavior, Amsterdam, v. 28, n. 5, p. 1535-1546, set. 2012.

CUNHA, Magali N. Do púlpito às mídias sociais: evangélicos na política e ativismo digital. Curitiba: Prismas, 2017.

DUARTE, Tatiane S. A participação da Frente Parlamentar Evangélica no legislativo brasileiro: ação política e (in)vocação religiosa. Ciências Sociais e Religião, Porto Alegre, v. 14, n. 17, p. 53-76, jul./dez. 2012.

EVELAND, William P.; MOREY, Alyssa C.; HUTCHENS, Myiah J. Beyond deliberation: new directions for the study of informal political conversation from a communication perspective. Journal of Communication, Oxford, v. 61, n. 6, p. 1082-1103, dez. 2011.

FERNANDES, Marcella. 0 dia em que deputados transformaram a Câmara em culto antiaborto. Huffpost, 12 jul. 2016. Mulheres. Não paginado. Disponível em: <https://goo.gl/5VAwNf>. Acesso em: 28 jun. 2017.

FRESTON, Paul. Evangélicos na política brasileira. Religião e Sociedade, Rio de Janeiro, v. 16, n. 1-2., p. 26-44, 1992. 
GILLESPIE, Tarleton. The politics of 'platforms'. New Media and Society, New York, v. 12, n. 3, p. 347-364, 2010.

GIUMBELLI, Emerson. A presença do religioso no espaço público: modalidades no Brasil. Religião e Sociedade, Rio de Janeiro, v. 28, n. 2, p. 80-101, 2008.

GRAHAM, Todd; WITSCHGE, Tamara. In the search of online deliberation: towards a new method for examining the quality of online discussions. Communications, Berlin, v. 28, n. 2, p. 173-204, 2003.

GUIMARÃES, Bruno M. A. O riso bate à porta: o humor de "Porta dos Fundos" e a crítica à religiosidade cristã contemporânea. 2016. 142 f. Dissertação (Mestrado em Comunicação Social) - Faculdade de Filosofia e Ciências Humanas, Universidade Federal de Minas Gerais, Belo Horizonte, 2016.

HALPERN, Daniel; GIBBS, Jennifer. Social media as a catalyst for online deliberation? Exploring the affordances of Facebook and YouTube for political expression. Computers in Human Behavior, Amsterdam, v. 29, n. 3, p. 1159-1168, maio 2013.

KARNAL, Leandro. Pecar e perdoar. Deus e o homem na história. Rio de Janeiro: Harper Collins, 2017.

MAIA, Rousiley C. M.; REZENDE, Thaiane A. S. Respect and disrespect in deliberation across the networked media environment: examining multiple paths of political talk. Journal of Computer-Mediated Communication, Oxford, v. 21, n. 2, p. 121-139, mar. 2016.

MARIANO, Ricardo. Laicidade à brasileira: católicos, pentecostais e laicos em disputa na esfera pública. Civitas, Porto Alegre, v. 11, n. 2, p. 238-258, mai./ago. 2011.

MARIANO, Ricardo; ORO, Ari Pedro. Introdução ao dossiê: religião, política, espaço público e laicidade no Brasil. Cultura y Religión, Santiago, v. 7, n. 2, p. 4-12, jun./dez. 2013.

MARQUES, Angela C. S. Dimensões do processo comunicativo na deliberação on-line. In: MENDONÇA, Ricardo F.; PEREIRA, Marcus A.; FILGUEIRAS, Fernando. (Orgs.). Democracia digital: publicidade, instituições e confronto político. Belo Horizonte: Editora UFMG, 2016. p. 237-262.

MARQUES, Angela. C. S.; MARTINO, Luís Mauro S. Mídia, ética e esfera pública. Belo Horizonte: Selo PPGCOM, 2016.

MARTín-BARBERO, Jesús. Dos meios às mediações: comunicação, cultura e hegemonia. Trad. de Ronald Polito e Sérgio Alcides. Rio de Janeiro: Editora UFRJ, 2009.

MARTINO, Luís Mauro S. Mídia, religião e sociedade: das palavras às redes digitais. São Paulo: Paulus, 2016.

MENDONÇA, Ricardo F.; AMARAL, Ernesto F. L. Racionalidade online: provimento de razões em discursos virtuais. Opinião Pública, Campinas, v. 22, n. 2, p. 418-445, ago. 2016.

MONTERO, Paula. Controvérsias religiosas e esfera pública: repensando as religiões como discurso. Religião e Sociedade, Rio de Janeiro, v. 32, n. 1, p. 167-183, 2012.

Religião, laicidade e secularismo. Um debate contemporâneo à luz do caso brasileiro. Cultura y Religion, Santiago, v. 7, n. 2, jun/dez, p. 13-31, 2013. 
OLIVEIRA, Wesley M.; SARMENTO, Rayza; MENDONÇA, Ricardo F. Deliberação no YouTube? Debates em torno da questão LGBT. Compolítica, Rio de Janeiro, v. 1, n. 4, p. 53-80, jan./jul. 2014.

PANOTTO, Nicolás. Religiones, política y Estado laico: nuevos acercamientos para el contexto latino-americano. Bogotá: Redlad; Santiago: Gemrip, 2017.

SARMENTO, Rayza; MENDONÇA, Ricardo F. Disrespect in online deliberation: inducing factors and democratic potentials. Revista de Ciência Política, Santiago, v. 36, n. 3, p. 705-729, 2016.

TAYLOR, Charles. Uma era secular. Trad. de Nélio Schneider e Luiza Araújo. São Leopoldo: Editora Unisinos, 2010.

0 que significa secularismo? In: ARAUJO, Luiz B. L.; PEREIRA, Taís S.; MARTINEZ, Marcela B. (Orgs.). Esfera pública e secularismo: ensaios de filosofia política. Rio de Janeiro: EdUERJ, 2012.

VAN DIJCK, José. Facebook as a tool for producing sociality and connectivity. Television \& New Media, New York, v. 13, n. 2 , p. 160-176, mar. 2012.

VITAL, Christina; LOPES, Paulo V. L. Religião e política: uma análise da atuação de parlamentares evangélicos sobre direitos das mulheres e de LGBTs no Brasil. Rio de Janeiro: Fundação Heinrich Böll, Instituto de Estudos da Religião, 2013.

WAIZBORT, Leopoldo. Elias e Simmel. In: . (Org.). Dossiê Norbert Elias. São Paulo: Edusp, 2001. p. 89-112.

WILLAIME, Jean-Paul. Sociologia das religiões. Trad. de Lineimar Pereira Martins. São Paulo: Editora Unesp, 2012.

WITSCHGE, Tamara A. C. (In)difference online: the openness of public discussion on immigration. 2007. 175 f. Tese (Doutorado em Ciências Sociais e Comportamentais) - Faculty of Social and Behavioural Sciences, Amsterdam School of Communication Research, University of Amsterdam, Amsterdam, 2007. Disponível em: <https://goo.gl/9KSzZe>. Acesso em: 20 set. 2017.

. Examining online public discourse in context: a mixed method approach. Javnost: The public, Ljubljana, v. 15, n. 2, p. 75-92, 2008.

From confrontation to understanding: in/exclusion of alternative voices in online discussion. Global Media Journal, Berlim, v. 1, n. 1, p. 1-22, 2011.

Texto recebido em 31.08.2017 e aprovado em 09.11.2017. 